\title{
Conventional versus alternative pig production assessed by multicriteria decision analysis
}

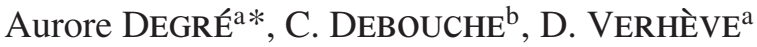 \\ ${ }^{a}$ Chaire de Technologie, Université de Mons-Hainaut, 17 place Warocqué, 7000 Mons, Belgium \\ ${ }^{\mathrm{b}}$ Unité de Mécanique des fluides et environnement, Faculté universitaire des Sciences agronomiques, 2 passage des Déportés, 5030 Gembloux, Belgium
}

(Accepted 19 December 2006)

\begin{abstract}
Differentiated quality and respect for the environment seem to be linked implicitly, but there is no demonstration of this concept for pig production. Pig production takes on different forms. Conventional pig production occurs side by side with some productions of "differentiated qualities" that are encouraged by the European Union as well as by nations. At the same time, the EU and nations are imposing environmental limitations concerning, for instance, the management of nitrogen and respect for neighbours. Here, we compared environmental impacts of 3 types of production: conventional production, organic production and free-range production. We took into account the process performances of 21 farms in the Walloon Region, Belgium. We compared the global process performances by multicriteria analysis. A jury of 16 experts was questioned to assign a relative importance to the emissions of ammonia, greenhouse gases, molecular nitrogen, odour and nitrogen to effluents. We found that the highest weighting was assigned to the $\mathrm{N}$ content of effluents, then to odour diffusion, the emission of ammonia, the emissions of greenhouse gas and finally, the emission of molecular nitrogen got a weak weighting. Our results showed that the relative ordering obtained was: (1) free-range production, (2) organic production and (3) conventional production. Nevertheless, within every sample a significant variability in the performances was observed. The same method applied within every sample enabled the creation of sub-groups. After reordering, we found that the most effective farms of every system of production were classified as top of the class. Thus, our original approach showed that on average the production of differentiated qualities was more environmentally effective than the conventional production. However, the variability of the performances within a system of production was high and it was quite possible for the conventional farms to reach results comparable with those of the best organic and free-range operations.
\end{abstract}

differentiated quality / organic farming / free-range farming / nitrate Directive / ammoniac / odour / Electra III

\section{INTRODUCTION}

The Walloon Region covers the southern half of Belgium. Belgium is a Federal State and its environment and agriculture policies, including the promotion of agricultural production, are regional competencies. In the environmental field, the Region transposed the 1991 European Directive on the protection of water against nitrate pollution (EEC, 1991) into the programme for the sustainable management of nitrogen in agriculture (MRW, 2002). In 1999, the Region passed a decree on the environmental permit bringing together all the operating conditions of the establishments it authorises. This decree aims at ensuring "the protection of the population against the dangers and harmful effects of establishments" (MRW, 1999). As regards the promotion of agricultural production, the Region has filed a Community trademark "Eqwalis" (EEC, 1994). This trademark can be put on products whose production specification has been approved by the Walloon Government. The latter has laid down minimal rules of production, stricter than the legislation in force, to which such specifica-

\footnotetext{
*Corresponding author: degre.a@fsagx.ac.be
}

Present address: Aurore Degré, Hydrologie et hydraulique agricole, Faculté des Sciences agronomiques de Gembloux, 2 passage des Déportés, 5030 Gembloux, Belgium. tions must subscribe. Such products are then known as being "of differentiated quality".

During the last few years, a large amount of studies have been published aiming at evaluating and comparing environmental performances of conventional and organic productions (Petersen et al., 2006; Castellini et al., 2006; Wood et al., 2006; van Diepeningen et al., 2006). A commonly accepted hypothesis links the differentiation of production to better environmental performance. It is demonstrated in the case of crop rotations (Petersen et al., 2006). Nevertheless, some conclusions of the cited authors are in contradiction with this hypothesis. The conclusions of Wood et al. (2006), for example, emphasise the global impacts of organic farming, such as greenhouse gas emissions and landscape disruption, which are greater than those of conventional farming. Ivanova-Peneva et al. (2006) present similar findings, working on organic farms with pregnant sows. Lansink and Reinhard (2004) showed that the emissions in conventional pig production systems can be limited by using the best available techniques. In the porcine sector, Basset-Mens and van der Werf (2004) compared three scenarios of production in France. Their conclusions are dependent on the functional unit chosen. Organic production presents better results when expressed per hectare or agricultural area, but this scenario presents poor results when expressed per $\mathrm{kg}$ of 
meat produced. Concerning this, Halberg et al. (2005) drew some conclusions about the assessment tools for the evaluation of livestock production in Europe. Behind all the differences existing between these tools, they underline the major rule of the functional unit chosen for the construction of indicators in the results obtained. Their recommendations are to use different functional units according to the global or local character of the emissions taken into account.

Bassey-Mens and van der Werf (2004) recommend more comparative studies of this kind to assess the environmental impacts of marginal production systems. Here, we firstly compare three typical pig productions systems in the Walloon region. Following the recommendations of Halberg et al. (2005), we will use three functional units (see below).

Secondly, we will try to bypass the traditional presentation of results and to aggregate the different categories of impacts. For the aggregation step, two ways can be followed (Shärlig, 1985). The first one uses utility functions (monetarisation is an example of this first way) (Van Calker et al., 2005). The second one uses a multicriteria decision model. (Norese, 2005). The first method aims at obtaining a numerical indicator of the global performance of the systems tested. The second method aims at obtaining a ranking between the different scenarios considering their relative performances. This last method is more flexible (Beccali et al., 2003) and presents several advantages: it helps decision-makers to be consistent with their objectives; it uses transparent assessment procedures; it facilitates the accomplishment of the decisional process even if the criteria are complex, contradictory or qualitative.

This article proposes an original approach to rank comparatively conventional pig production, organic pig production and labelled production (free-range pork). For now, the parameters are nitrogen assessment, ammonia, greenhouse gas emissions and the radius of odour discomfort. These concerns are largely discussed in the literature as the most significant impacts of porcine production (Schauberger et al., 2001; Béline and Martinez, 2002; Wolter et al., 2004; Haeussermann et al., 2006). However, the method can be enlarged similarly in the future to take into account new criteria on economic and social concerns. It can also be adapted to other production methods.

\section{MATERIALS AND METHODS}

\subsection{Samples}

This study is based on a sample of 21 pork-producing farms: 7 organic farms, 7 free-range farms and 7 conventional farms. The organic specification is of European origin (EC, 1999). The free-range pork specification is of Walloon origin and a private initiative. The Walloon Government has approved both of these specifications as being of differentiated quality. The conventional production strictly meets the legislative requirements. The conventional farms were randomly chosen but the size of the sample was restricted by the limited availability of organic farms. This must be taken into account while reading the conclusions of this article.
An analysis of the environmental management of these farms was made with meetings and interviews of the 21 farm holders. Every flow of the products mentioned, e.g. animals, feed and manure purchases and sales; crop yield, animal growth, etc., is transformed into a flow of nitrogen by means of a database with more than 1200 reference values from the literature (Debouche and Lambin, 2002). These values are wellknown constants (nitrogen content for a given kind of chemical fertiliser) or are variables in time and in space (the quantity of nitrogen contained in $110 \mathrm{~kg}$ of pork). The latter values are used like random variables and linked to a variation coefficient (Debouche and Lambin, 2002). On the basis of this information, nitrogen flows were modelled. We considered the farm divided into three compartments: cultivated soil (root zone), crops and animals. We also considered that the farm interacts with the following: the air, deep soil, surface and underground water, and other elements.

If, for a given compartment on the farm, all flows can be simulated, their verification is possible on the basis of an equation for the conservation of mass. This equation can reveal a closure gap, providing an indication of the quality of the models used. On the contrary, if a flow is not simulated, the closing of the balance will allow for its assessment while cancelling out the closure gap. This is done for the flow of nitrogen leaving cultivated soil for the deep soil and underground waters. The mathematical models used for the calculation of these flows are presented in Debouche and Lambin (1999). Data from Groot Koerkamp and Uenk (1997), Guillou et al. (1993), Kermarrec (2000), Ni et al. (1996) and Nicks et al. $(2003,2004)$ were also used. Let's note that the data presented by the above cited authors have been achieved under experimental conditions, sometimes far removed from actual conditions, but remain nevertheless interesting indications and the only alternative to on-the-spot measurements.

\subsection{Functional unit}

Before going any further, we should define the functional units in relation to which the identified emissions are expressed (AFNOR, 1994; ISO, 1997). Haas et al. (2000) and Cooper (2003) encourage the use of more than one functional unit, since an activity's function is seldom one-dimensional. Following the recommendations of Halberg et al. (2005), we have adopted three functional units: one hectare of agricultural land (for flows relating to farm production with local impact), one fattened pig ready to go to the slaughterhouse, the contribution of the sow included (for flows relating only to porcine production with global impact - acidification, greenhouse effect, etc.) and one farm for the radius of odour discomfort. Indeed, the radius of odour discomfort cannot be expressed in metres per pig as this would not make any physical sense, in addition to the fact that only the immediate local residents experience the discomfort and it does not impact consumers as a whole. 


\subsection{Criteria definitions}

Criteria are indicators enabling the consequences of an action to be grasped and summarised (Roy and Bouyssou, 1993). For each criterion, different parameters have to be defined: its purpose; the unit adopted for the numerical values or another scale used; the optimisation direction (is one looking to maximise or to minimise this value?); the thresholds of Indifference, Q, and of Preference, P, and the threshold of Veto, V.

These thresholds enable the data's variability to be taken into account. Indeed, the simplest multicriterion methods use true criteria. This means that if a difference in performance of a criterion exists (these actions being equivalent on all the other criteria), Action $\mathbf{A}$ is preferred to Action $\mathbf{B}$, provided its score on the criterion in question is higher than that of $\mathbf{B}$. However, marginal differences can be due to the data's variability. It is more reasonable to admit that marginal differences between two actions on a criterion translate into indifference (Sharlig, 1985; Roy and Bouyssou, 1993). The Indifference Threshold, $\mathbf{Q}$, is the largest variation compatible with indifference between two actions. The use of such a threshold transforms true criteria into quasi-criteria.

It would also be arbitrary, when the variation exceeds $\mathbf{Q}$, to move abruptly from the indifference between two actions to a strict preference for one action over another. To avoid this abrupt transition, an area of weak preference has been introduced by means of the Preference Threshold, $\mathbf{P}$. Threshold $\mathbf{P}$ is the minimal variation compatible with strict preference for one action over another. The use of such a threshold transforms the quasi-criterion into a pseudo-criterion.

In this application, we are setting Threshold $\mathbf{P}$ at the value of the policy objectives relating to the criterion $(7.5 \%$ reduction of greenhouse gases and $31 \%$ reduction of ammonia), which were officially set by the Region under the Kyoto and Gothenburg Protocols. In this way, when two actions are compared, Action $\mathbf{A}$ will be preferred to Action $\mathbf{B}$ if it presents a degree of progress in relation to $\mathbf{B}$, such as progress indicating that the policy objective will be met. Threshold $\mathbf{Q}$ is half of Threshold P. Lastly, the Veto Threshold, V, defines the score that cannot be accepted in any circumstances. We are setting the Veto Threshold at an increase of $200 \%$ of the score of the action of reference on this criterion. Thus, for any given criterion, Action $\mathbf{B}$ will never be preferable to Action $\mathbf{A}$ if, in a minimisation objective, its score is $200 \%$ above that of $\mathbf{A}$ for one of the criteria. Thresholds $\mathbf{Q}$ and $\mathbf{V}$ are fixed arbitrarily but let's note that in the following application, the threshold $\mathrm{V}$ will never interfere in the ranking process.

\section{Acidifying gas}

For ammonia emissions (acidifying gas), the criterion is the quantity of such gas produced $\left(\mathrm{kg} \mathrm{NH}_{3} \cdot \mathrm{pig}^{-1}\right)$.

\section{Greenhouse gas}

Greenhouse gas emissions (GGE) include emissions of methane, nitrogen protoxide and carbon dioxide, coming primarily from the animals' breathing. This emission is not taken into account by the IPCC since the breathing of pigs is impossible to avoid and belongs to a short cycle of $\mathrm{CO}_{2}$ (consumption by crops used for animal feeding) (IPCC = international panel on climate change). However, in our comparative study, the time of residence of the animals can vary from 4 to more than 9 months and thus become a factor of comparison, which is not negligible. Internationally accepted weighting coefficients (Berger, 1992) were used to calculate the number of kilograms of equivalents to the emitted $\mathrm{CO}_{2}$ $\left(\mathrm{kg} \mathrm{eq} \mathrm{CO}_{2} \cdot \mathrm{pig}^{-1}\right)$.

\section{Molecular nitrogen}

Molecular nitrogen is not a pollutant. It is, however, taken into account as a loss of raw material for agricultural activity, since the organic lack of nitrogen in the soil is usually compensated for by the spreading of synthetic mineral nitrogen, at a considerable energy cost (Bockman et al., 1990). This emission is expressed in kilograms of molecular nitrogen per pig $\left(\mathrm{kg} \mathrm{N}_{2}\right.$.pig ${ }^{-1}$ ). The emission value is deduced from the closing of the nitrogen balance.

\section{Odours}

Odours are not expressed as quantities of emitted matter. As odour is a nuisance, we have considered the pig farm's radius of odour discomfort. Among the various existing methods for evaluating this radius (see, for example, Schauberger et al. (2001)), we have selected the RUG method (Nicolas, 2002). This method takes not only the number of animals into account, but also the type of building, the ventilation, the area in which the pig farm is established, etc. It is an empirical method based on Belgian observations which allows its use in our case. The result is a distance expressed in metres from the edge of the livestock building and at which the odour is regarded as acceptable (inferior to one odour unit per cubic metre). It would make no physical sense to relate the distance to the number of animals, since there is no simple proportionality between the two figures. So we are using the distance as is, referring to our third functional unit: the whole farm (m).

\section{Nitrogen in the effluents}

The nitrogen component of the effluents spread on the land is taken into account. The value of the criterion is the quantity of nitrogen spread per agricultural hectare of land minus $170 \mathrm{~kg} N$ per hectare (maximum value authorised by Directive 91/676/EEC (EEC, 1991)) insofar as the effluents spread are used as manure and become pollutants beyond this quantity. The value of the criterion is brought back to zero when the spreading is lower than $170 \mathrm{~kg} \mathrm{~N}$ per hectare $\left(\mathrm{kg} \mathrm{N} \cdot \mathrm{ha}^{-1}\right)$.

For all the criteria, the objective is to minimise the value of the criterion. 


\subsection{Multicriterion analysis}

The multicriterion approach introduced by Roy (1985) has since been widely used in environmental matters (Roy and Bouyssou, 1993; Maystre et al., 1994; Hokkanen and Salminen, 1997; Bousson, 2003; Norese, 2005). It lends itself particularly well to such matters because of the multiplicity of potential impacts and their incomparability, the multitude of players involved in the decision and the expectations that are dependent upon it (Maystre et al., 1994). Multicriterion Analysis rests on a series of scenarios, also called alternative actions, compared with each other and in a family of criteria in relation to which the scenarios are evaluated. The choice between the various methods is based:

- on the aim of the application (isolation of the best actions, sorting the actions into different categories or ranking them);

- on the data's variability (use of true criteria, use of quasicriteria and use of pseudo-criteria).

Our objective is to rank the farming systems in relation to each other on the basis of their environmental performance, not to sort them or to identify the best conforming one. As performance evaluation is tainted by major variability, we used pseudo-criteria. Taking into account these parameters and following the recommendations in Maystre et al. (1994), the Electra III method of ranking on the basis of pseudo-criteria was selected.

\subsection{Electra III method}

The Electra III method uses a set of alternatives $(\mathbf{A}, \mathbf{B}, \mathbf{C}$, etc.: in our case, organic, free-range and conventional) and a set of criteria $(\mathrm{g})$. The criteria are evaluated for each alternative. Depending on whether the target is to minimise or maximise the criteria, the lower or the higher it is, the better the alternative meets the criterion in question (Hokkanen and Salminen, 1997). The evaluation procedure consists of comparing each alternative with the other ones.

In the comparison of alternative $\mathbf{A}$ with alternative $\mathbf{B}$, if $\mathbf{g}(\mathbf{A})$ and $\mathbf{g}(\mathbf{B})$ are the criterion values of alternatives $\mathbf{A}$ and $\mathbf{B}$ according to the criterion $\mathrm{g}$,

- $\mathbf{g}(\mathbf{A})>\mathbf{g}(\mathbf{B})+\mathrm{p}(\mathrm{g})$ means that alternative $\mathbf{A}$ is preferred to alternative $\mathbf{B}$ according to this criterion;

$-\mathbf{g}(\mathbf{B})+\mathrm{q}(\mathrm{g})<\mathbf{g}(\mathbf{A}) \leq \mathbf{g}(\mathbf{B})+\mathrm{p}(\mathrm{g})$ means that alternative $\mathbf{A}$ is weakly preferred to alternative $\mathbf{B}$ according to this criterion;

$-\mathbf{g}(\mathbf{A}) \leq \mathbf{g}(\mathbf{B})+\mathrm{q}(\mathrm{g})$ means that alternative $\mathbf{A}$ and alternative $\mathbf{B}$ are indifferent according to this criterion.

where $\mathrm{p}(\mathrm{g})$ and $\mathrm{q}(\mathrm{g})$ are the preference and the indifference threshold, respectively, for the $\mathrm{g}$ criterion.

The concordance index according to criterion $\mathrm{g}$ is 1 in the first case, comprises between 0 and 1 (linear interpolation) in the second case and is 0 in the third case.

A global concordance index is calculated as a weighted mean of the concordance index for each criterion using their relative weight (see below).
A discordance index is calculated for each criterion $\mathrm{d}(\mathrm{g})$. Its value is

-0 if $\mathbf{g}(\mathbf{B})-\mathbf{g}(\mathbf{A}) \leq \mathrm{p}(\mathrm{g})$

-1 if $\mathbf{g}(\mathbf{B})-\mathbf{g}(\mathbf{A})>\mathrm{v}(\mathrm{g})$

- between 0 and 1 (linear interpolation) if $\mathrm{p}(\mathrm{g})<\mathbf{g}(\mathbf{B})-$ $\mathbf{g}(\mathbf{A}) \leq \mathrm{v}(\mathrm{g})$

where $\mathrm{v}(\mathrm{g})$ is the veto threshold.

And finally, the degree of outranking for the hypothesis of "A is preferred to B" is calculated on the basis of the global concordance index $(\mathrm{C})$, and the discordance index for the set of criteria $\mathbf{J}$ for which it is superior to $\mathrm{C}$ (Eq. (1)).

$$
\delta(A, B)=C \Pi_{g \in J} \frac{1-d(g)}{1-C} .
$$

This degree of outranking is calculated for each comparison between two actions. It allows the ranking of the different alternatives. The Electra III method is based on two distillations. A descending distillation ranks the actions from best to worst. At each stage of calculation, one or more actions are positioned at the top of the list. They are withdrawn from the list. The rest of the actions undergo the calculation procedure again until all the actions have been exhausted. An ascending distillation ranks, in the same way, the actions from worst to best. The final partial pre-order is the intersection of the two complete pre-orders that have been established. It is based on three practical rules:

- If Action $\mathbf{A}$ is preferred to Action $\mathbf{B}$ in the two complete pre-orders, it is also preferred to it in the final pre-order.

- If Action $\mathbf{A}$ is preferred to Action $\mathbf{B}$ in one of the preorders and is the equivalent of it in the other, it is also preferred to it in the final pre-order.

- If Action $\mathbf{A}$ is preferred to Action $\mathbf{B}$ in one of the preorders and Action $\mathbf{B}$ is preferred to it in the other, these two actions will be considered to be incomparable.

\subsection{Criteria weighting}

The Electra III method enables the criteria to be weighted according to their relative importance. Weighting techniques have been widely studied by Mousseau $(1992,1993)$. Many techniques are based on expert experience. The opinions of experts have also been developed in various multi-discipline studies when conflicts existed with regard to the perception of the various impacts and in the absence of legal points of reference (Tamura et al., 1994; Ghyym, 1999; Petit and van der Werf, 2003; Carey et al., 2003). In our case, a legal framework regulates the spreading of nitrogen on agricultural land but neither odours nor various potentially atmospherepolluting emissions are regulated. However, this last point is the principal cause for refusing environmental permits, owing to the strong reaction of local residents in public opinion surveys (Degré et al., 2004).

A jury of experts was constituted to evaluate the relative weights of these emissions. Oliver (2002) shows that the definition of the word "expert" varies in each jury. Nevertheless, some references are available in the literature concerning the 
constitution of the jury (Murry and Hammons, 1995): having specialised knowledge, having professional experience or representing an involved association. They also recommend a number of 10 to 25 members. Concerning juries made up of scientists, Mohorjy and Aburizaiza (1997) and Marggraf (2003) used the number of scientific papers published to select the jury members.

In our case, we wanted to reflect the opinion of all the stakeholders of the porcine sector in the Walloon Region. We made up a jury of 16 members distributed into four groups: scientists, representatives of the public authorities and administrations, producers and third parties (citizens and local residents). The scientists are the ones in the region who have published the most on the actual topic. The representatives of the public authorities and administrations were designated by the Walloon ministers concerned. The producers were chosen by the three agricultural groups implicated in our study. The citizens were represented by their federation of associations. Unfortunately, it was not possible to find a representative for the local residents' associations (there is no such federation). The solution adopted was to synthesise all the local resident's interventions during information sessions held prior to the construction of new pig farms in the region from February 1992 until February 2002 to estimate the opinion of a virtual representative of the local residents.

We used a Delphi method of individual and iterative questioning such as those presented by Schmidt et al. (2001) and Okoli and Pawlowski (2004). Three questions were devoted to each criterion. They related to the need for legislation framing the emission concerned, the urgency and the degree of severity required in this field. The experts were invited to adopt a position on a quantified scale during an individual interview. They then received their positions by way of feedback plus the average position of the jury, with an indication of the dispersion in the answers. They were invited to review or confirm their positions by justifying them if they were outside a defined interval around the average. At the end of this operation, convergence had been reached, meaning that the experts had arrived at widely accepted weighting values.

\subsection{Multicriterion analysis}

In the first instance, the Multicriterion Analysis procedure was applied to the average performance of the three specifications. In the second instance, the Multicriterion Analysis procedure was applied within each sample: the actions are the farms and their individual performances. The objective was to constitute three sub-groups in each sample: Sub-group A of the farms presenting the best performances, Sub-group C of the farms presenting the worst performances and Sub-group B of the farms presenting intermediate performances. In this manner, we wanted to take account of the differences between the farms within the same specification whilst avoiding the consideration of individual cases. In the third instance, the Multicriterion Analysis was applied to the nine sub-groups.

\section{RESULTS AND DISCUSSION}

\subsection{Farm profiles}

\section{The organic farms}

Organic farms are very diverse and are quite often linked to direct retail outlets. Pork is often a small production to complete the offer to the customer. The mean size of porcine livestock on organic holdings is 12 sows for a production of 196 fattened pigs per year. Pigs have a daily mean growth of $514 \mathrm{~g} / \mathrm{d}$. The farms contain a herd of nursing cows with a mean size of 11 cows and a herd of dairy cows with a mean size of 28 cows. Meat production is complemented by a mean production of 250 chickens present for 3.6 months and 210 laying hens producing 60900 eggs per year. Dairy production is partly transformed into cheese, butter and yogurt. The coproduce is used to feed the animals.

The mean surface of the farms is 47.9 hectares. This surface is mainly grassland: $75.1 \%$, of the surface of which $47 \%$ is temporary grassland; and cereals: husk, wheat, oat, rye and barley for a total of $18.4 \%$. Animal feedstuffs are derived from both cultivation and grassland and are also purchased as organic feed, mainly for pigs and poultry. This feed must meet the specifications for organic farming and seems to have a less optimal composition than that available on the labelled farms and on intensive farms. No mineral fertiliser is used on the farm. On the basis of these factors, the mean efficiency for every culture, the indications of growth of the animals and the composition of feed purchased, and the flows and balances of nitrogen within the holding are calculated.

\section{The free-range farms}

Farms producing labelled pigs have an average of 30 sows and 500 fattened pigs per year. Pigs have a daily mean growth of $642 \mathrm{~g} / \mathrm{d}$. Three of the seven farms have a herd of nursing cows with an average of 26 head. A farm holds a dairy herd of 42 head. The mean surface of the farms is 49 ha. This surface is occupied by winter wheat (30\%), grassland (19\%), sugar beets (14\%), corn (10\%), barley and linen (6\%), etc. Two farmers feed fattening pigs with corn crop mix (CCM). On the other five farms, fattening pigs are fed exclusively with commercial feed satisfying the requirements of the label. Sows are fed with conventional commercial feed or with cereals from the farm itself.

\section{The conventional farms}

The conventional pig farms of our sample are intensive and show little diversification. The mean size of pork livestock is 145 sows and 2270 fattening pigs per year. Pigs have a mean growth of $552 \mathrm{~g} / \mathrm{d}$. However, striking differences can be noticed (from 464 to $644 \mathrm{~g} / \mathrm{d}$ ) depending on whether the breeders use or not by-products from the agro-food industry or a specific feedstuff. Philippe et al., 2006 observed $736 \mathrm{~g} / \mathrm{d}$ using specific feedstuff in laboratory conditions. Three of the seven farms have dairy herds averaging 66 cattle head, 
and their production is sold in the form of milk. The mean surface of the farms is 42.40 ha. The land is given over to grassland (38\% of the surface) and to silage corn $(43 \%)$. The feed for the pigs comes from commercial channels or from by-products of the agro-food industry.

\section{Flows and balances}

Table I presents the flows and the resulting balances expressed in kilograms of nitrogen per hectare of agricultural surface used as well as the coefficients of variation for these flows and balances. Free-range pork farms presented the smallest quantity of nitrogen spread per hectare, given the larger surface areas available in such farms. Conventional farms, on the other hand, reached extremely high spreading levels. It should be noted, however, that the figures represent the state of play before the introduction of the Walloon Region's first Action Plan that followed the transposition of the Nitrates Directive (EEC, 1991). This data should be updated at the end of said Action Plan in 2007.

Ammonia emissions into the atmosphere were higher in pig farms using straw litters than in those using slatted floors according to Philippe et al. (2007). Conventional farms kept their pigs exclusively on slatted floors, while organic farms kept theirs exclusively on straw litters. In free-range pork farms, both straw and partially slatted floors were used.

Greenhouse gas emissions increased from organic pork to conventional pork; $\mathrm{N}_{2} \mathrm{O}$ emissions were preponderant. This is comparable with the results of Wolter et al. (2004). The emissions are greater from slurry under a slatted floor than from straw litter (Nicks et al., 2003, 2004; Nicks, 2004). Molecular nitrogen emissions were higher in the organic and freerange pork farms as a result of the use of straw litters. This is coherent with the results of Béline (1998) who showed that molecular nitrogen is produced by the composting of the straw directly beneath the animals and by the nitrification and denitrification reactions. As regards odour emissions, both the size of conventional farms and the type of buildings used were highly unfavourable. Organic farms often contained distinctly fewer animals and the use of litters was often a favourable factor for reducing odour emissions.

\subsection{Performance table}

The performance table of each of the farms for the production of a finished fattened pig is presented in Table II. One sees the difficulty of ordering the systems on the basis of this performance table. The conventional farms seem to be the worst but their performances concerning NH3 emission are quite good. Between organic and free-range farms, the choice is quite impossible: organic farms have the advantage concerning greenhouse gases and odour but free-range farms have the advantage concerning $\mathrm{NH}_{3}, \mathrm{~N}_{2}$ emissions and $\mathrm{N}$ spreading to the soil.

\subsection{Criteria weightings}

The five selected criteria have to be weighted. Recourse to a jury of experts enabled their relative importance to be quantified. The results of the expert interviewing procedure are given in Table III. The spreading of effluents was preponderant for the jury since legislation on the matter already exists. Among the other factors to be weighted, the experts attached the highest importance to odours. They consider that the fear of odours is the principal reason for local residents' opposition to pig farm projects and the principal impediment to the sector's development. These conclusions are comparable with that of Petit and van der Werf (2003). Ammonia emissions were ranked after odours in order of importance. The jury was indeed of the view that the agricultural sector, and especially porcine production, were responsible for ammonia emissions in the Walloon region. Greenhouse gas emission was ranked lower in the order of importance. The porcine sector is not the main cause of these emissions and if efforts are to be made to achieve the goals laid down at the international level, porcine production is not the most concerned. The members of the jury were unanimous in considering nitrogen emission as relatively unimportant according to its non-polluting nature.

\subsection{Multicriterion analysis}

The first ranking chart obtained is given in Figure 1. Figure 2 gives the results of the Multicriterion Analysis applied to the nine sub-groups. We have allotted a name to them made up of the first letter of their specification plus the letter A, B or C. An analysis of the results' solidity was made using the sets of weightings of each of the four sub-sections of the jury. The small variations in weighting do not give rise to any major change in the ranking.

In order to interpret Figures 1 and 2, one should consider that for any point, the abscissa is the action's order number at the end of the descending distillation and the ordinate is the action's order number at the end of the ascending distillation. The final order, considering both distillations, is obtained graphically by a perpendicular projection on the bisectrix of the angle of origin. In the case of Figure 1, as the two rankings are identical, the points are located on the bisectrix. In Figure 2, a difference between the descending and the ascending rankings leads to a divergence of the point in relation to the bisectrix. This divergence reflects the incomparability of the action that the point represents.

Figure 1 shows that in terms of the overall averages, freerange farm performances outrank those of the other farms. The organic pork farms are ranked in an intermediate position and the conventional farms rank lowest in this classification. This result, however, conceals any disparities between farms within the same specification. If we apply the same multicriterion procedure to the farms of each sample, we see that in relation to the established criteria, differences exist between the performances of farms working according to the same specification. This supports the conclusions of Hayes et al. (2006), who show the variability between production sites in pigs' units. On 
Table I. Flows of nitrogen $\left(\mathrm{kg} \mathrm{N} \cdot \mathrm{ha}^{-1}\right)$ for three types of farms and their coefficient of variation.

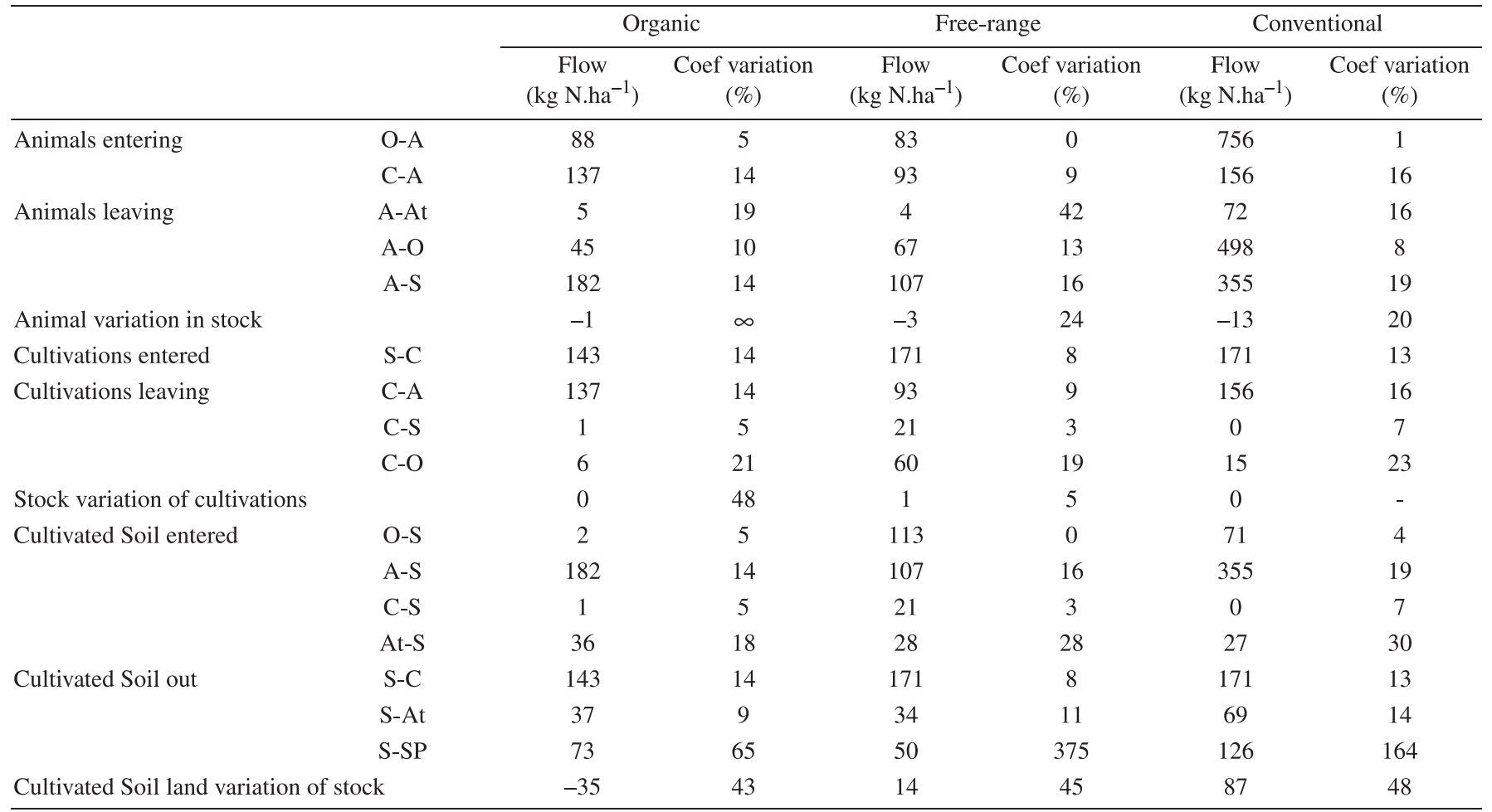

In the compartment "animals" the entries of nitrogen taken into account are:

- O-A: inputs of nitrogen from the other businesses (purchase of animals, of feedstuffs, etc.),

- C-A: inputs of nitrogen from the cultures (animal feed, straw of the litters, etc.).

Under the heading "animals" we take the following exits of nitrogen into account:

- A-At: atmospheric emissions by animals, buildings and storage of sewage,

- A-O: exports toward other businesses (sale of livestock, export of sewage, sale of derivative products (eggs, milk, etc.)),

- A-S: exits toward cultivated soils (evacuations onto grassland and spreading of sewage),

In the compartment "animals", the variation in stock is calculated on the basis of:

-variation in the number of animals and animal growth,

- storage of sewage.

In the compartment "cultures" nitrogen inputs taken into account are:

- S-C: mineral nutrition of the plant productions from the cultivated soil.

In the compartment "cultures" nitrogen exits taken into account are:

- C-A: consumption by the animals (feed of the animals, straw of the litters, etc.),

- C-S: restitutions to soil (rests of cultivations, green manures, etc.),

- C-O: exits toward the other businesses (sale of plant production).

In the compartment "cultures" variation of stock consists of storage of plant matter.

In the compartment "soil cultivated" nitrogen input taken into account is:

- O-S: purchase of mineral fertiliser or recovery of slurry from other businesses,

- A-S: contributions by animals (evacuations onto grassland and spreading of sewage).

- C-S: contribution from cultivation (remains of cultivations, green manures, etc.),

- At-S: contributions from the atmosphere (dry and humid deposits).

In the compartment "soil cultivated" exits taken into account are:

- S-C: mineral nutrition of the plant productions toward cultivations,

- S-At: atmospheric emissions,

- S-SP: losses to underground waters and deep soil.

In the compartment "cultivated soil" variation in stock of mineral nitrogen takes in:

- Organisation of residues buried and of sewage spread,

- Mineralisation and reorganisation of nitrogen in the soil. 
Table II. Average environmental performance per production system.

\begin{tabular}{lccccc}
\hline Actions & \multicolumn{4}{c}{ Criteria } \\
\cline { 2 - 6 } & $\mathrm{NH}_{3}$ & $\begin{array}{c}\mathrm{GGE} \\
\left(\mathrm{kg} \mathrm{NH}_{3} \mathrm{pig}^{-1}\right)\end{array}$ & $\begin{array}{c}\mathrm{N}_{2} \\
\left(\mathrm{~kg} \mathrm{~N}_{2} \mathrm{pig}^{-1}\right)\end{array}$ & $\begin{array}{c}\text { Od } \\
(\mathrm{m})\end{array}$ & $\begin{array}{c}\mathrm{N} \\
\mathrm{kg} \mathrm{N}^{-} \mathrm{ha}^{-1}>170\end{array}$ \\
\hline ORG & 2.74 & 354.5 & 4.29 & 76 & 23.3 \\
FR & 1.97 & 365.5 & 2.36 & 89 & 0 \\
CON & 1.56 & 405.4 & 1.02 & 103 & 186.8 \\
\hline
\end{tabular}

Table III. Relative weightings of the criteria adopted by the jury of experts expressed in \%.

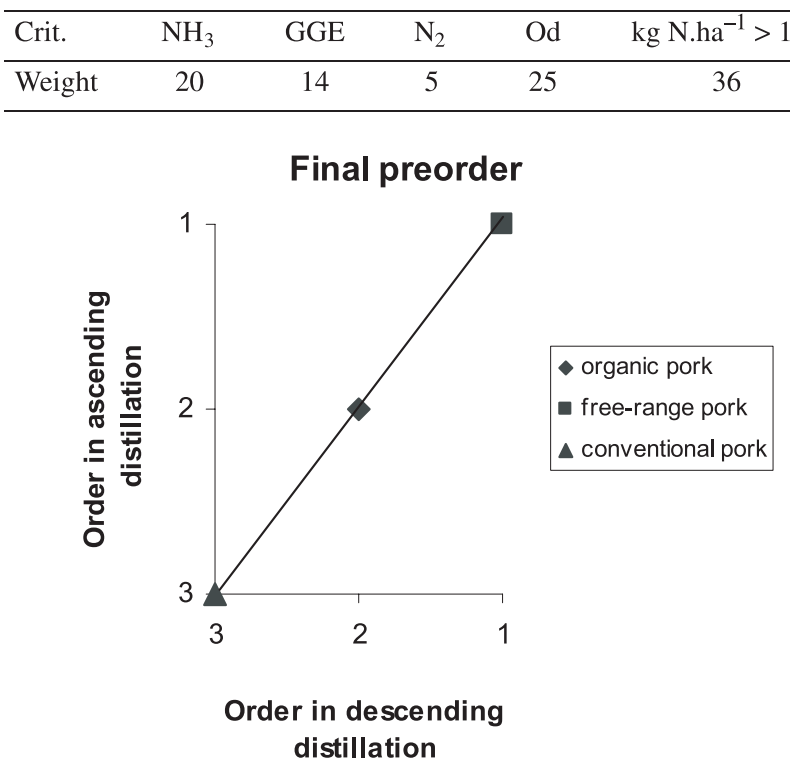

Figure 1. Ranking chart of the three overall averages. For any point, the abscissa is the action's order number at the end of the descending distillation and the ordinate is the action's order number at the end of the ascending distillation. A descending distillation ranks the actions from best to worst. At each stage of calculation, one or more actions are positioned at the top of the list. They are withdrawn from the list. The rest of the actions undergo the calculation procedure again until all the actions have been exhausted. An ascending distillation ranks, in the same way, the actions from worst to best. The final order, considering both distillations, is obtained graphically by a perpendicular projection on the bisectrix of the angle of origin.

the basis of these observations and in order not to pursue reflections on individual cases, we have classified each group of farms into three sub-groups.

The application of multicriterion analysis to these nine subgroups is presented in Figure 2. We see that the best organic farms (Group OA) rank first for both distillations, followed by the best group of free-range pork farms. The best conventional farms come third, as do Group FC and Group BB; these last two, however, have a higher level of incomparability. The farms in Groups CB and CC share the bottom place in the ranking. The variability in performance between the farms working according to the same specification is such that it is

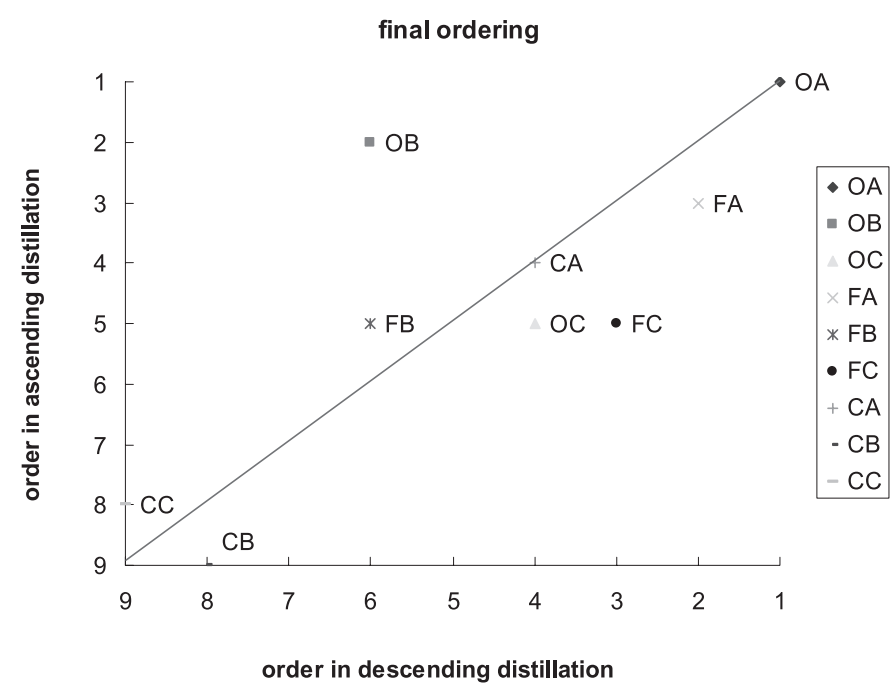

Figure 2. Chart of the ranking obtained between the nine sub-groups (the first letter is the initial of the production system, the second letter is the sub-group: A: the farms with the best performances in their production system; B: the farms with intermediate performances in their production system; C: the farms with the worst performances in their production system).

impossible to claim that organic and free-range pork farms perform systematically better environmentally than conventional farms. The best farms for each form of production come first and show that it is possible, regardless of the production choices, to meet environmental policy objectives in the area of porcine production. The implicit starting hypothesis is therefore disproved. The factors explaining this result are to be found in the descriptions of the farms.

The organic producers had extremely diversified farms and often offered direct sales on the farm requiring a wide range of products, and their livestock was relatively reduced. They were unable to use modern emission-reducing techniques. Their technical level was limited. In addition, these farms were subject to a constraining specification, particularly for the formulation of feed.

The conventional pork producers, on the other hand, presented distinctly less diversification. Their pig stock was large, enabling the installation of emission-reducing measures at the level of the building and the feed (to which only legal constraints now apply). Lansink and Reinhard (2004) showed how these technical changes are efficient at reducing emissions. 
The stockbreeders' level of technicality, especially in the CA farms, was very high. The size of the livestock has negative consequences, however, on the potential radius of odour discomfort. It should be noted that at the time of our field investigation (January 2003), the conventional farms were spreading huge quantities of organic nitrogen on their land (up to over $400 \mathrm{~kg}$ per hectare per annum). The transposition of the Nitrates Directive (EEC, 1991) has undoubtedly restricted such spreading.

The free-range pork farms were in an intermediate position. Their pig stock was relatively small. Sales were handled by marketing co-operatives. These farms achieved a good level of technicality, and their specification was less constraining concerning the formulation of feed. The reduced size of the livestock and the use of litters were factors that reduced the risk of odours. Basset-Mens and van der Werf (2004) present similar conclusions at the end of their life-cycle assessment of three contrasting pig farm systems. They showed significant margins of improvement for each scenario of pig production.

\section{CONCLUSION}

The implicitly accepted hypothesis according to which differentiated quality productions have a lower impact on the environment than conventional productions served as the basis for this work. We evaluated the emissions into the atmosphere and the nitrogen assessment of the 21 actual farms in the Walloon Region producing pork in a conventional manner and according to two differentiated quality specifications. We referred to the existing legal texts and to the Walloon Region's official intentions of establishing evaluation criteria for such farms. We weighted these criteria with the help of a jury of experts. These experts ranked atmospheric emissions in order of importance. Ammonia odours and emissions were regarded as preponderant. Greenhouse gas emissions were of average importance and molecular nitrogen emissions (regarded as a loss of raw materials for agriculture) were of minimal importance. A Multicriterion Analysis of the Electra III variety made on the averages of the three groups showed that the free-range and organic farms were ahead of the conventional farms. However, the heterogeneity of the farms encouraged the search for a finer classification. Each group was divided into three subgroups according to the quality of their environmental performance. The relative ranking of the nine sub-groups showed that the best conventional pig farms were close to the best organic and free-range pig farms. We can conclude that whatever the quality of production concerned, the environmental policy objectives can be met. The starting hypothesis is therefore disproved. Conventional farms can introduce emissionlimitation strategies that could not be envisaged in the smaller, diversified farms. The conventional farmers' technical level of competence is potentially higher, given the specialisation of their production. For further research it is necessary to complete this approach with other criteria dedicated to the economic and social assessment of the three production systems, but the methodology for weighting criteria and ranking alternatives can be the same.

\section{REFERENCES}

AFNOR (1994) Dictionnaire de l'environnement, Les termes normalisés, Association française de normalisation, $307 \mathrm{p}$.

Basset-Mens C., van der Werf H.M.G. (2004) Scenario-based environmental assessment of farming systems: the case of pig production in France, Agr. Ecosyst. Environ. 105, 1-2, 127-144.

Beccali M., Cellura M., Mistretta M. (2003) Decision making in energy planning, Application of the Electra method at regional level for the diffusion of renewable energy technology, Renew. Energ. 28, 2063-2087.

Béline F. (1998) Étude des transferts d'azote par nitrificationdénitrification au cours du traitement aérobie et du stockage du lisier de porc, Essai avec 15N, Université de Perpignan, Thèse de doctorat, $153 \mathrm{p}$.

Béline F., Martinez J. (2002) Nitrogen transformation during biological aerobic treatment of pig slurry: effect of intermittent aeration on nitrous oxide emission, Bioresource Technol. 83, 225-228.

Berger A. (1992) Le climat de la Terre, Bruxelles, Belgique, De Boeck Université, $472 \mathrm{p}$.

Bockman O.C., Kaarstad O., Lie O.H., Richards I. (1990) Agriculture and fertilizers, Norsk Hydra as Agricultural Group.

Bousson E. (2003) Gestion forestière intégrée, Approche basée sur l'analyse multicritère, Les presses agronomiques de Gembloux, $303 \mathrm{p}$.

Carey P.D., Short C., Morris C., Hunt J., Priscott A., Davis M., Finch C., Curry N., Little W., Winter M., Parkin A., Firbank L.G. (2003) The multi-disciplinary evaluation of a national agri-environment scheme, J. Environ. Manage. 69, 71-91.

Castellini C., Bastianoni S., Granai C., Dal Bosco A., Brunetti M. (2006) Sustainability of poultry production using the emergy approach: comparison of conventional and organic rearing systems, Agr. Ecosyst. Environ. (in press).

Cooper J.S. (2003) Specifying functional units and reference flows for comparable alternatives, Int. J. LCA 8, 337-349.

Debouche C., Lambin J. (1999) Écobilan de l'exploitation agricole, Manuel d'utilisation, Faculté des Sciences agronomiques de Gembloux, Direction Générale de l'Agriculture de la Région wallonne, 132 p. + annexes.

Debouche C., Lambin J. (2002) L'écobilan de l'exploitation agricole, $7^{\mathrm{e}}$ colloque international des spécialistes francophones en évaluation d'impacts, Liège, 10-14 juin 2002. www.fsagx.ac.be/mf.

Degré A., Debouche C., Verheve D. (2004) Importance relative des impacts sur l'atmosphère des élevages porcins : les arbitrages des experts, $4^{\mathrm{e}}$ journée Productions porcines et avicoles, 20.10.04, pp. $42-52$.

EC (1999) Council regulation 1804/1999 of 19 july 1999 supplementing regulation EEC 2092/91on organic production of agricultural products and indication refeering thereto on agricultural products and foodstuffs to include livestock production, JO L222 of 24.08.99.

EEC (1991) Council directive 91/676/EEC of 12 december 1991 concerning the protection of water against pollution caused by nitrates from agricultural sources, JO L375 of 31.12.91.

EEC (1994) Council regulation 40/94 of 20 december 1994 on community trademarks, JO L011 of 14.01.94. 
Ghyym S.H. (1999) A semi-linguistic fuzzy approach to multi-actor decision making: application to aggregation of experts judgments, Ann. Nucl. Energy 26, 1097-1112.

Groot Koerkamp P.W.G., Uenk G.H. (1997) Climatic conditions and aerial pollutants in and emission from commercial animal production systems in the Netherlands, in: Ammonia and odour emission from animal production facilities, 6-10 October 1997, Vinkerloord, The Netherlands, pp. 139-144.

Guillou D., Dourmad J.-Y., Noblet J. (1993) Journées de la recherche porcine en France 25, 307-314.

Haas G., Wetterich F., Geier U. (2000) Life cycle assessment framework in agriculture on the farm level, J. LCA. 5, 345-348.

Halberg N., van der Werf H.M.G., Basset-Mens C., Dalgaard R., de Boer I.J.M. (2005) Environmental assessment tools for the evaluation and improvement of European livestock production systems, Livest. Prod. Sci. 96, 33-50.

Haeussermann A., Hartung E., Gallmann E., Jungbluth T. (2006) Influence of season, ventilation strategy and slurry removal on the methane emission from pig houses, Agr. Ecosyst. Environ. 112, $115-121$

Hayes E.T., Curran T.P., Dodd V.A. (2006) Odour and ammonia emission from intensive pig units in Ireland, Bioresource Technol. 97, 940-948.

Hokkanen J., Salminen P. (1997) Choosing a solid waste management system using multicriteria decision analysis, Eur. J. Oper. Res. 98 , $19-36$.

ISO (1997) Environmental management, Life cycle assessment, Principles and framework, Norme ISO 14040 1997-06-15, 12 p.

Ivanova-Peneva S.G., Aarnink A.J.A., Verstegen M.W.A. (2006) Ammonia and mineral losses on dutch organic farms with pregnant sows, Biosyst. Eng. (in press).

Kermarrec C. (2000) Bilan et transformation de l'azote en élevage intensif de porcs sur litière, Thèse de doctorat, Université de Rennes, $185 \mathrm{p}$.

Lansink A.O., Reinhard S. (2004) Investigating technical efficiency and potential technological change in Dutch pig farming, Agr. Syst. 79, 353-367.

Marggraf R. (2003) Comparative assessment of agri-environmental programmes in federal states of Germany, Agr. Ecosyst. Environ. 2100, $1-10$.

Maystre L.Y., Pictet J., Simos J. (1994) Méthodes multicritères ELECTRA, Description, conseils pratiques et cas d'application à la gestion environnementale, Presses polytechniques et universitaires romandes, Collection gérer l'environnement, 323 p.

Mohorjy A.M., Aburizaiza O.S. (1997) Impact assessment of an improper effluent control system: a delphi approach, Environ. Impact Assess. Rev. 17, 205-217.

Mousseau V. (1992) Analyse et classification de la littérature traitant de l'importance relative des critères en aide multicritère à la décision, Operations Res. 26, 367-389.

Mousseau V. (1993) Problèmes liés à l'évaluation de l'importance relative des critères en aide multicritère à la décision : réflexions théoriques, expérimentations et implémentations informatiques, Thèse de doctorat, Université Paris-Dauphine.
MRW (1999) Décret du 11 mars 1999 relatif au permis d'environnement, Ministère de la Région wallonne M.B. 08.06.1999.

MRW (2002) Arrêté du Gouvernement wallon du 10 octobre 2002 relatif à la gestion durable de l'azote en agriculture, Ministère de la Région wallonne M.B. 29.11.02.

Murry J.W., Hammons J.O. (1995) Delphi: a versatile methodology for conducting qualitative research, Rev. Higher Educ. 18, 424-436.

Ni J., Berckmans D., Vinckier C. (1996) Influence of contaminated floor on ammonia emission from pig house, in: Proceeding of the Agricultural-Engineers 1996 congress, Madrid 96B-062.

Nicks B. (2004) Aspects environnementaux et zootechniques de l'élevage de porcs charcutiers et de porcelets sevrés sur litières accumulées de paille et de sciure, Liège, ULg, Thèse de Doctorat, 202 p.

Nicks B., Laitat M., Vandenheede M., Désiron A., Verhaeghe C., Canart B. (2003) Emission of ammonia, nitrous oxide, methane, carbon dioxide and water vapour in the raising of weaned pigs on strawbased and sawdust-based deep litters, Anim. Res. 52, 299-308.

Nicks B., Laitat M., Farnir F., Vandenheede M., Désiron A., Verhaeghe C., Canart B. (2004) Gaseous emission from deep litters pens with straw or sawdust for fattening pigs, Anim. Sci. 78, 99-107.

Nicolas J. (2002) Étude comparative entre les différentes méthodes d'estimation de la distance minimum d'implantation pour des bâtiments d'élevage par rapport aux zones d'habitat et aux habitations isolées, Fondation universitaire luxembourgeoise, mai 2002, 92 p.

Norese M.F. (2005) ELECTRA III as a support for participatory decisionmaking on localisation of waste-treatment plants, Land Use Policy (in press).

Okoli C., Pawlowski S.D. (2004) The Delphi method as a research tool: an example, design considerations and applications, Inform. Manage. 42, 15-29.

Oliver I. (2002) An expert-panel based approach to the assessment of vegetation condition within the context of biodiversity conservation Stage 1: the identification of conditions indicators, Ecol. Indicators $27,1-15$.

Petersen S.O., Regina K., Pollinger A., Rigler E., Valli L., Yamulki S., Esala M., Fabbri C., Syvasalo E., Vinther F.P. (2006) Nitrous oxide emission from organic and conventional crop rotations in five European countries, Agr. Ecosyst. Environ. 112, 200-206.

Petit J., van der Werf H.M.G. (2003) Perception of the environmental impacts of current and alternative modes of pig production by stakeholder groups, J. Environ. Manage. 68, 377-386.

Philippe F.X., Laitat M., Vandenheede M., Canart B., Nicks B. (2006) Comparaison des performances zootechniques et du contenu en azote de l'effluent lors de l'élevage de porcs charcutiers sur caillebotis ou sur litière de paille accumulée, Ann. Med. Vet. 150, $137-144$.

Philippe F.X., Laitat M., Canart B., Vandenheede M., Nicks B. (2007) Comparison of ammonia and greenhouse gas emissions during the fattening of pigs, kept either on fully slatted floor or on deep litter, Livest. Sci. (in press)

Roy B. (1985) Méthodologie multicritère d'aide à la décision, Éditions Economica, $423 \mathrm{p}$.

Roy B., Bouyssou D. (1993) Aide multicritère à la décision: Méthodes et cas, Éditions Economica, 695 p. 
Schärlig A. (1985) Décider sur plusieurs critères : Panorama de l'aide à la décision multicritère. Collection Diriger l'entreprise 1. Presses polytechniques et universitaires romandes, Lausanne, $304 \mathrm{p}$.

Schauberger G., Piringer M., Pertz E. (2001) Separation distance to avoid odour nuisance due to livestock calculated by the austrian odour dispersion model (AODM), Agr. Ecosyst. Environ. 87, 13-28.

Schmidt R.C., Lyytinen K., Keil M., Cule P. (2001) Identifying software project risks: an international Delphi study, J. Manage. Inform. Syst. $17,5-36$.

Tamura H., Fujita S.-I., Koi H. (1994) Decision analysis for environmental impact assessment and consensus formation among conflicting multiple agents - including case studies for road traffic, Sci. Total Environ. 153, 203-210.
Van Calker K.J., Berentsen P.B.M., Romero C., Giesen G.W.J., Huirne R.B.M. (2005) Development and application of a multi-attribute sustainability function for Dutch dairy farming systems, Ecol. Econ. (in press).

Van Diepeningen A.D., de Vos O.J., Korthals G.W., van Bruggen A.H.C. (2006) Effects of organic versus conventional management on chemical and biological parameters in agricultural soils, Appl. Soil Ecol. 31, 120-135.

Wolter M., Prayitno S., Schuchardt F. (2004) Greenhouse gas emission during storage of pig manure on a pilot scale, Bioresource Technol. 95, 235-244.

Wood R., Lenzen M., Dey C., Lundie S. (2006) A comparative study of some environmental impacts of conventional and organic farming in Australia, Agr. Syst. 89, 324-348. 